times result in spurious high frequency oscillations, ${ }^{2}$ laboratories trying to reproduce these results will need the unstated filter settings used by the authors.

The authors show examples of the ripples and artifacts prior to filtering, which suggest proper settings were chosen. Three of their patients were evaluated with scalp and intracranial recordings, showing agreement between the SOZ in each. Given that prior studies of ripples were performed with depth electrode recordings, it is unfortunate that those data were excluded from the present study.

We look forward to reading more about that data, which would link prior studies to the present conclusions, in the near future. The next important steps are determining the relationship between scalp recorded ripples and surgical outcome, and perhaps to automating the method to increase interrater reliability. ${ }^{3}$

Author Response: Jean Gotman, Montreal; Luciana Andrade-Valenca, Pernambuco, Brazil; Rina Zelmann, Francois Dubeau, Montreal: Goldenholz et al. asked about our filter, which is a Finite Impulse Response filter of order 63. They also inquired about the relationship between scalp HFOs and those recorded in intracerebral electrodes. This is a complex problem for 2 reasons. First, we do not have simultaneous scalp and intracerebral recordings. Secondly, intracerebral electrodes record from a small brain volume and it is unlikely that HFOs seen at one intracerebral contact could be visible on the scalp. As we discussed, ${ }^{1} \mathrm{HFO}$ visible on the scalp may come from rare HFOs that occur synchronously over a relatively large area (3 or $4 \mathrm{~cm}^{2}$ ). We are currently analyzing simultaneous scalp and subdural recordings to further understand the relationship between intracerebral and scalp signals. Finally, Goldenholz et al. mention the need for automatic detection of scalprecorded high frequencies. We refer them to our recently published method. ${ }^{4}$ We hope that HFOs may become a marker of the epileptogenic zone and a marker of developing epileptogenesis after an initial brain injury.

Copyright (C) 2012 by AAN Enterprises, Inc.

1. Andrade-Valenca LP, Dubeau F, Mari F, Zelmann R, Gotman J. Interictal scalp fast oscillations as a marker of the seizure onset zone. Neurology 2011;77:524-531.

2. Benar CG, Chauviere L, Bartolomei F, Wendling F. Pitfalls of high-pass filtering for detecting epileptic oscillations: a technical note on "false" ripples. Clin Neurophysiol 2010; 121:301-310

3. Blanco JA, Stead M, Krieger A, et al. Unsupervised classification of high-frequency oscillations in human neocortical epilepsy and control patients. J Neurophysiol 2010;104: $2900-2912$.

4. von Ellenrieder N, Andrade-Valenca LP, Dubeau F, Gotman J. Automatic detection of fast oscillations $(40-200 \mathrm{~Hz})$ in scalp EEG recordings. Clin Neurophysiol Epub 2011 Sep 20.

5. Jacobs J, Zijlmans M, Zelmann R, et al. High-frequency electroencephalographic oscillations correlate with outcome of epilepsy surgery. Ann Neurol 2010;67:209-222.

\section{PSYCHOGENIC NONEPILEPTIC SEIZURES IN US VETERANS}

Selim Benbadis, Tampa, FL: The findings of this study $^{1}$ are very important, if not surprising. It has been well known that the delay for diagnosis of psychogenic nonepileptic seizures is unacceptably long, and this suggests that it is even worse for veterans. This is partly because when veterans have any episode and a history of head injury, the assumption is that they have post-traumatic epilepsy $(58 \%$ of patients in the study). This finding illustrates a larger problem of a "gap" in epilepsy care. Since the use of EEG-video for diagnosis is so delayed, it is very likely that veterans do not benefit from nondrug treatments for intractable epilepsy (i.e., epilepsy surgery and vagus nerve stimulation).

The same general rule should be followed in veterans as in the general population of seizure patients: if seizure-like episodes do not respond to medication, the diagnosis should be questioned. Many historical red flags can raise suspicion, and then-if the episodes are frequent enough-the diagnosis should be verified by EEG-video monitoring. If prolonged EEG-video monitoring is not available, outpatient EEG-video with induction can also be used and provides a similar yield. ${ }^{2,3}$

Copyright (C) 2012 by AAN Enterprises, Inc.

1. Salinsky M, Spencer D, Boudreau E, et al. Psychogenic nonepileptic seizures in US veterans. Neurology 2011;77:945950.

2. Benbadis SR, Siegrist K, Tatum WO, et al. Short-term outpatient EEG video with induction in the diagnosis of psychogenic seizures. Neurology 2004;63:1728-1730.

3. Varela HL, Taylor DS, Benbadis SR. Short-term outpatient EEG-video monitoring with induction in a Veterans Administration population. J Clin Neurophysiol 2007;24:390391.

NORMAL PRESSURE HYDROCEPHALUS: MEASURE TWICE, SHUNT ONCE

Aunali S. Khaku, Kenneth M. Heilman, Gainesville, FL: In his editorial, Dr. Scharre ${ }^{1}$ stated "Cognitive impairment in NPH [...] typically results in [...] low verbal fluency (less than 13 animals named in 1 minute)." The statement suggests that patients 


\section{Neurology}

\section{Psychogenic Nonepileptic Seizures in US Veterans Selim Benbadis \\ Neurology 2012;78;225 \\ DOI 10.1212/01.wnl.0000410957.06758.43}

This information is current as of January 16, 2012

Updated Information \& Services

References

Permissions \& Licensing

Reprints including high resolution figures, can be found at: http://n.neurology.org/content/78/3/225.1.full

This article cites 3 articles, 2 of which you can access for free at: http://n.neurology.org/content/78/3/225.1.full\#ref-list-1

Information about reproducing this article in parts (figures,tables) or in its entirety can be found online at:

http://www.neurology.org/about/about_the_journal\#permissions

Information about ordering reprints can be found online: http://n.neurology.org/subscribers/advertise

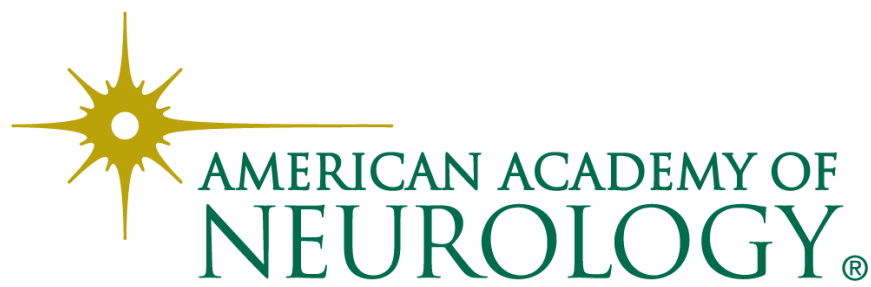

